\title{
DEA Model Construction and Investment Efficiency Analysis of Overseas Electric Power Market in Clean Energy
}

\author{
Chao $\mathrm{Ma}^{1, \mathrm{a}}$ \\ ${ }^{1}$ (SPIC Huanghe Hydropower Development Co., Ltd., Xining, Qinghai 810000)
}

\begin{abstract}
The paper aims to further explore the current situation of Chinese investment in overseas clean energy and analyze the development of the power industry in the field of clean energy. The paper elaborates the present development status of clean energy based on the Data Envelopment Analysis (DEA) model and investment efficiency theories, analyzing the potential risks taken by China's electric power industry from the investment in overseas clean energy and calculating the power enterprises' investment efficiency. The results reveal that China's overseas investment in clean energy has developed rapidly. However, from 2016 to 2017 , due to the accelerated investment in clean energy, the comprehensive investment efficiency of clean energy has dropped significantly, to $79.1 \%$ and $78.7 \%$, respectively. Subsequently, the comprehensive investment efficiency increased significantly, reaching 80.4\% in 2019. Between 2015 and 2019, effective investment in clean energy has reached the highest, 32\% in 2015, while there are more ineffective investments in 2016. After 2017, the proportion of power enterprises' investment in clean energy has increased significantly, accounting for $32 \%$ in 2019. In future development, the proportion of investment in this field will continue to rise. Hence, clean energy boasts good development prospects.
\end{abstract}

\section{Introduction}

Currently, the environmental issue has become one of the primary public concerns. Since the industrial revolution, machines have replaced manpower on a large scale. Along with the dramatic increase in productivity, energy consumption and environmental pollution also grow increasingly serious [1], with large consumption of fossil fuels, increasing carbon dioxide emissions, and serious global warming occurring [2] . With the worsening environmental problem, people have gradually come to realize that in modern society, it is the implementation of sustainable development strategy that provides the fundamental way out for social development [3]. Clean energy is characterized by low pollution, low emission and no secondary pollution. Replacing traditional fossil energy with clean energy undoubtedly plays a significant role in relieving the environmental pollution caused by energy consumption [4].

Clean energy industry is booming in China. Since 1997 when the Energy Law of the People's Republic of China was promulgated, China, during the past over 20 years, has issued nearly a hundred laws and regulations related to clean energy, aiming to encourage the development of clean energy at the policy level [5]. In the electric power industry, the proportion of clean energy in the total electric power production in China is also increasing year by year. By 2017, the proportion of clean energy in the total electric power production in
China has reached about $28.5 \%$.With the acceleration in global economic integration, China actively participates in the international competition and cooperation, obtaining more opportunities for economic boom.

In this context, Chinese enterprises also vigorously pursue development and step into the international market in terms of investment, and the electric power industry becomes one of the important components of the enterprises making investment abroad [6]. Due to the particularity of the investment in overseas clean energy, the investment efficiency definitely makes the hot issue considering the operation and development of electric power enterprises. Therefore, it is of enormous significance and application value to conduct scientific and effective research on the efficiency of Chinese enterprises' investment in overseas clean energy [7].

Based on the DEA model, this paper analyzes the investment efficiency of electric power enterprises' investment in overseas clean energy, designs the corresponding DEA evaluation indices and evaluation model, and fully discusses the current situation of electric power enterprises' investment in clean energy. The research intends to provide scientific and effective reference materials for China's electric power enterprises investing overseas. 


\section{Approaches}

\subsection{Investment analysis of clean energy market}

Clean energy mainly includes nuclear energy and a large amount of renewable energy which consists of hydro energy, wind energy, biomass energy, solar energy, geothermal energy and ocean energy, etc. [8]. The specific categories are shown in Figure 1 below.

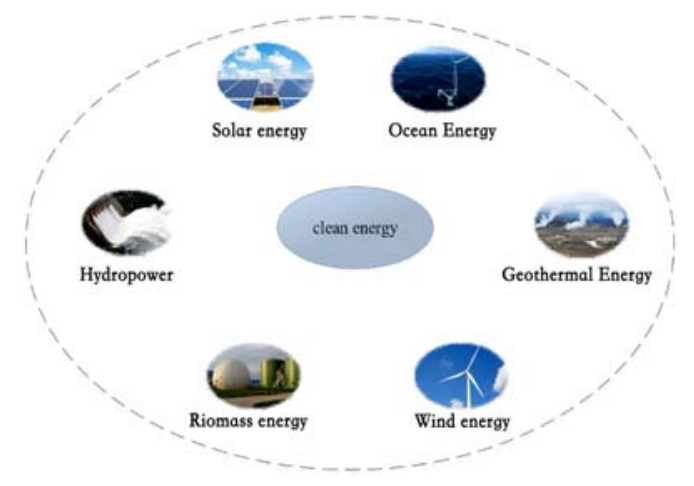

Figure 1. The main categories of clean energy

In recent years, due to the support of policies and the changed outlook, the share of clean energy in the market has gradually expanded, and clean energy has become the second largest energy in the world [9]. Relevant studies show that by the end of 2020, the global output value of clean energy will be as high as $\$ 2.4$ trillion, and the clean energy industry has become the world's third largest industry. In the next three years, the global scale of clean energy industry will increase by $1214 \mathrm{GW}$ [10]. In the clean energy industry, the most important issue is the utilization of clean energy. Clean energy resources are abundant, but the production and utilization of clean energy is often accompanied by the problem of high cost. Therefore, in the study of clean energy, reducing production cost and improving energy utilization efficiency have always been the focus of researchers [11]. In the investment field of power grid, the proportion of investment in clean energy is increasing year by year, while the proportion of investment in traditional photovoltaic and wind power is gradually decreasing. With the advancement of science and technology, smart grid and energy storage are developing rapidly, playing an important role in the establishment of the global energy system. During the investment in and the development of clean energy projects, it is necessary to focus on the pre-investment return and the comprehensive efficiency in the course of the operation [12]. These two points can reasonably evaluate the effectiveness of clean energy projects, so as to provide sufficient reference materials for the effectiveness analysis of clean energy projects and promote the rational development of clean energy projects.

Hydropower, nuclear power and wind power are the main parts of China's clean energy industry, and the total output value of these three industries accounts for more than $97 \%$ of the overall output value of clean energy [13]. As the development of the nuclear energy industry needs to focus on the safety of nuclear energy utilization, it is restricted by practical factors. Hydropower industry is the earliest and largest industry. China has formed a group of cascading reservoirs of considerable scale since the completion of water conservancy projects because of vast area, rich water resources and a large drop in terrain [14]. The wind industry, meanwhile, has received a lot of attention in recent years. From the regional perspective, China can be divided into seven major areas famous for clean energy production, namely, North China, Northeast China, China Dynamic Region, Central China, South China, Southwest China and Northwest China. Southwest China is rich in water resources and has numerous hydropower stations [15]. In the meantime, with the rapid development of the wind energy industry, the proportion of clean energy in Northwest China is gradually on the rise. Generally speaking, many clean energy projects, with mature industrial operation, have been set up in the western region, where the scale of the clean energy industry accounts for more than $50 \%$ of the total output of clean energy in China.

\subsection{Theoretical analysis of DEA model}

Data Envelopment Analysis (DEA) is a widely used method of statistical analysis [16]. The detailed analysis process is shown in Figure 2 below:

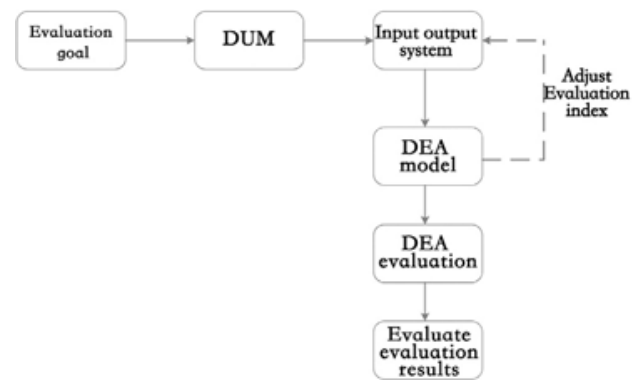

Fig. 2 Specific flow of traditional DEA analysis method

Fig. 2 shows that DEA model is particularly important in DEA analysis. A large number of studies have shown that DEA model can be applied to the evaluation of investment efficiency [17]. However, attention should be paid to the selection of decision-making units during evaluation, as the input and output of decision-making units to the social environment must be similar [18]. Linear programming is the main principle of DEA analysis. In the DEA model, each DMU only needs to calculate the objective function once to get the maximum value in this case, and the calculation method is objective. The flexibility of index selection is one of the most important advantages of DEA model, which can be used to conduct good and accurate analysis of non-financial indicators. The specific operating process of the traditional DEA model is as follows. First, the data set is set as:

$$
\text { Data set }=(Y, X)
$$

Where, $\mathrm{Y}$ is the output matrix $\left(\mathrm{K}^{*} \mathrm{~N}\right)$; $\mathrm{X}$ is the input matrix $\left(\mathrm{K}^{*} \mathrm{M}\right)$; $\mathrm{K}$ for $\mathrm{DMU} ; \mathrm{M}$ is input quantity; $\mathrm{N}$ is the quantity produced. 
For each DMU, its linear programming process is shown in Equation (2) :

$$
\begin{array}{cc}
\max & u^{\prime} y i \\
\text { s.t. } & v^{\prime} x i=1 \\
& u^{\prime} y k-v^{\prime} x k \leq 0 \\
& u \geq 0, v \geq 0
\end{array}
$$

In practice, the efficiency of DMU mainly refers to the distance from the boundary to the DMU. When the value of DMU is less than 1, it means that the efficiency of DMUJ is low. Assume that each DMU uses m inputs, $x i j$, and three $y r j s$, as is be defined below:

$$
\begin{aligned}
& D M U_{j}(j=1, \cdots, n) \\
& x_{i j}(i=1, \cdots, m) \\
& y_{r j}(r=1, \cdots, s)
\end{aligned}
$$

Where I and $r$ are indexes of the input and output. Based on the above formula, the input-output inefficiency formula can be expressed as follows:

$$
\begin{aligned}
& \frac{1}{m} \sum_{i=1}^{m} s_{i}^{-} / x_{i o} \\
& \frac{1}{n} \sum_{r=1}^{m} s_{r}^{+} / y_{r o}
\end{aligned}
$$

where, $s_{i}^{-}$is the excess of input and $s_{i}^{-}$means the inadequacy of output. As for the application of clean energy, clean energy can be seen as input, thus the environmental efficiency model of clean energy can be obtained. The specific content is shown in Formula (8) :

$$
\begin{gathered}
\theta^{*}=\min \theta \\
\text { s.t. } \quad \sum_{j=1}^{n} x_{i j} \lambda_{j}-s_{i}^{-}=\theta x_{i 0}, i=1, \cdots, m ; \\
\sum_{j=1}^{n} y r j \lambda j-s_{r}^{+}=\theta y_{r 0}, r=1, \cdots, s ; \\
\lambda_{j} \geq 0, j=1, \cdots, n .
\end{gathered}
$$

In addition to the traditional DEA, the commonly used DEA models include the improved DEA model and DEA window model. The improved DEA model is also known as the measurement of non-radial relaxation (SBM), and the expression of SBM is shown in Formula (9) and (10) :

$$
\begin{array}{cc} 
& \min h_{0} \\
\text { s.t. } & x_{0}=X \lambda+s^{+} \\
& y_{0}=Y \lambda-s^{-} \\
& \lambda_{j} \geq 0, s^{-} \geq 0, s^{+} \geq 0
\end{array}
$$

$$
\min h_{0}=\frac{1-\frac{1}{n}\left(\sum_{i=1}^{n} \frac{s_{i 0}^{-}}{x_{i 0}}\right)}{1+\frac{1}{m}\left(\sum_{r=1}^{m} \frac{s_{r 0}^{+}}{y_{r 0}}\right)}
$$

Where, $\mathrm{H}_{0}$ is the efficiency based on relaxation, and when $\mathrm{H} 0=1$, all the degrees of relaxation are 0 . The DEA window model can be used to evaluate the efficiency changes at the macro level, as shown in Equations (11) and (12):

$$
\begin{aligned}
& \omega_{1}=(1,2,3) \\
& \omega_{2}=(2,3,4) \\
& \cdots \\
& \omega_{T-1}=(T-2, T-1, T) \\
& E(T)=\frac{\omega_{1}+\omega_{2}+\omega_{3}}{3}
\end{aligned}
$$

Where, $\omega$ is the width of the evaluation, representing a window set every few years; $\mathrm{T}$ is the total year,

\subsection{Status quo of China's overseas power investment market}

Among the power grid enterprises with different business directions, whether they are power grid enterprises, power generation enterprises or energy enterprises, they have invested in a large number of related large-scale facilities and large-scale projects abroad. China's electric power enterprises are found in Myanmar, Laos, Cambodia, Brazil, Argentina and other places [19]. The gradual increase in the number of overseas power investment projects indicates that China's power industry has achieved remarkable performance in investing overseas, which promotes China's economic growth and social development. According to relevant investigation data, compared with domestic projects in the same period, the investment profit from foreign projects is much higher than that from the domestic ones [20]. Nonetheless, despite huge economic benefits, overseas projects may bring diverses risks which cannot be ignored. Due to the particularity of investing abroad and compared with ordinary investment, making investment overseas may cause special risks [21]. In general, The risks from the investment in overseas power projects mainly include political risk, economic risk, legal risk, social risk, natural risk, industry risk, management risk and financial risk, etc. [22]. Among them, political risk ranks as the biggest one because overseas projects tend to have a long construction period and foreign governments keep changing due to the political instability, which may cause the current government refuse to accept the investment projects of the previous government. Factors such as violence and war brought by political instability will have a negative impact on overseas investment projects, generating enormous economic losses [23]. Moreover, economic instability, social and cultural customs, legal 
constraints, bad natural environment and other problems of the country where the overseas project is located all restrict the investment in overseas enterprises. Furthermore, unlike domestic projects, overseas enterprises' daily management, actual technological application, industry competitions, financial situation and other risky factors also affect the investment cost and efficiency of overseas projects. Therefore, in practice, targeted attention should be paid to the investment efficiency of overseas projects.

\subsection{Theoretical analysis of investment efficiency}

The essence of investment is the increase in capital or the accumulation of social costs [24]. In economics, investment theories embrace dominance theory, internal theory and cycle theory [25]. Internal theory is the theory of market internalization. When an electric power enterprise invests in the international market, the external market in operation will be transformed into the internal market among the companies. The cycle theory mainly refers to the cyclical nature of products, and enterprises' investing overseas goes through the period of product innovation, product maturity and product standardization.

In light of relevant theories of economics, efficiency mainly refers to an evaluation method that optimizes the use of resources to meet the set expectations and needs under certain conditions such as capital input, technical support and investment environment [26]. Generally speaking, efficiency is the analysis of the effectiveness of resource utilization. A practical problem being studied can be discussed from two aspects of input and output. In this research direction, when the input cost is relatively less and the output yield is greater, it is admitted that the investment efficiency of the company has certain effectiveness [27].

\subsection{Establishment of evaluation indexes and the model for the efficiency of investment in overseas clean energy}

Based on such features of electric power enterprises' investing as huge amounts of investment and long operation cycle, this study selects appropriate input and output indexes and does an analysis of input and output. The specific details are shown in Table 1 below:

Table 1 Results of the research on input and output indicators

\begin{tabular}{lcc}
\hline & Name & Abbreviation \\
\hline Investment index & $\begin{array}{c}\text { Total assets } \\
\text { Total clean } \\
\text { energy } \\
\text { investment } \\
\text { Total long-term } \\
\text { equity } \\
\text { investment } \\
\text { Operating } \\
\text { income } \\
\text { Return on total } \\
\text { assets }\end{array}$ & TAEI \\
\hline
\end{tabular}

As can be seen from Table 1 above, the investment indicators of enterprises in this study are total assets (TA), total clean energy investment (TAEI) and total long-term equity investment (LEI). The total assets of an enterprise mainly contain the fixed assets, current assets, long-term investment, intangible assets and other assets. Since the overseas investment projects of electric power enterprises tend to have a long period and big investment risk, the total amount of long-term equity investment should be taken into account. The output of the enterprise mainly refers to the operating income (OI) and the return on total assets (RTA) of the enterprise. The operating income of an enterprise is the inflow of profits in the process of production, and it is an important indicator to measure the development of an enterprise. The return on assets, an important element in assessing the competitiveness of an enterprise, represents the earning ability of an enterprise.

Based on the above evaluation indicators and the basic structure of the DEA model, this paper selects the data of 11 listed electric power enterprises from 2015 to 2019 and calculates their comprehensive investment efficiency. The main methods of model calculation are shown in Figure 3 below:

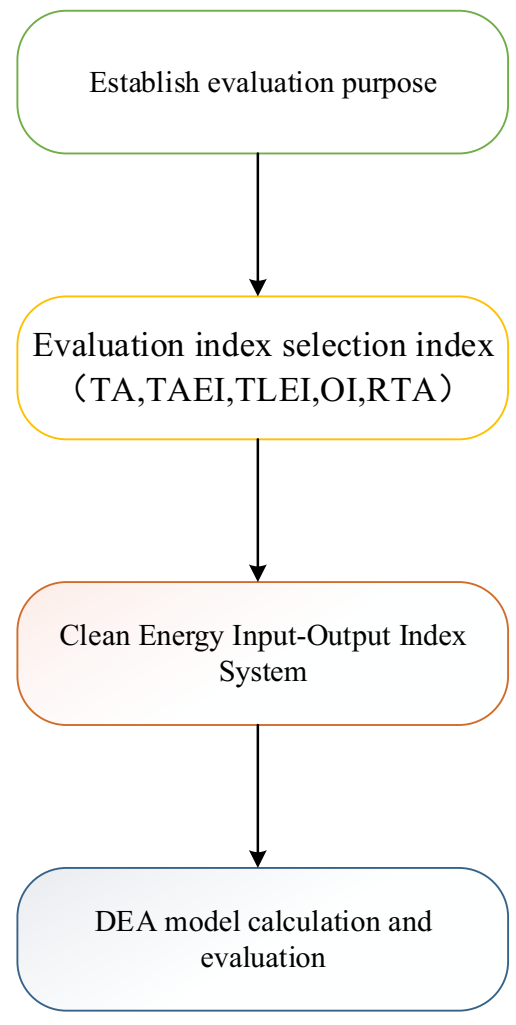

Fig. 3 Specific methods of DEA evaluation

As is displayed by Figure 3, firstly, the calculation and evaluation purposes of this study are set, then representative indicators are selected as DMU, and the index system of clean energy input-output is determined. Finally, the corresponding results are calculated based on the DEA model. 


\section{Results and discussion}

\subsection{Comprehensive efficiency analysis results of electric power enterprises}

To begin with, the research, based on the model analysis, calculates the comprehensive investment efficiency of electric power enterprises, which is shown in Figure 4 below.

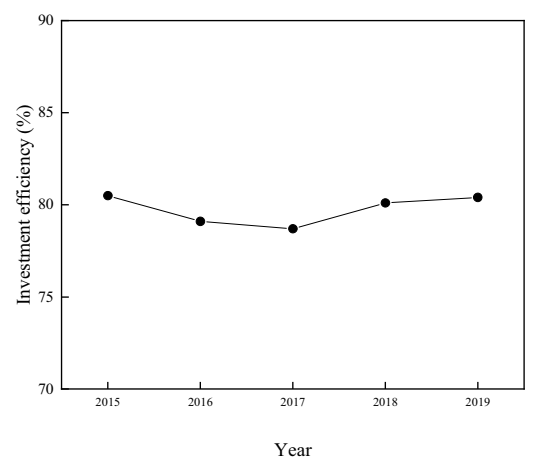

Figure 4. Comprehensive investment efficiency of clean energy of power enterprises from 2015- 2019

Fig. 4 shows that in 2015, the overall efficiency of China's clean energy investment was 80.5\%. From 2016 to 2017 , there was an obvious downward trend in the efficiency of clean energy investment, and the investors' efficiency in these two years was $79.1 \%$ and $78.7 \%$ respectively. In 2018 and 2019, the investment efficiency of clean energy shows an upward trend, which was $80.1 \%$ and $80.4 \%$ respectively. This is mainly because the year of 2016 witnessed the swift development in China's clean energy investment and the clean energy investment industry gained momentum overall. However, due to the gradual increase in the proportion of clean energy investment in some enterprises and the imperfect investment mechanism, the efficiency of investment was reduced. With the development and improvement of the clean energy industry, clean energy projects have been completed and put into use one after another, so the investment efficiency of clean energy has been significantly improved.

\subsection{Ratio of clean energy investment in power enterprises}

At the same time, the study also analyzes the proportion of effective investment in clean energy in the investment in clean energy. The specific results are shown in Figure 5 below:

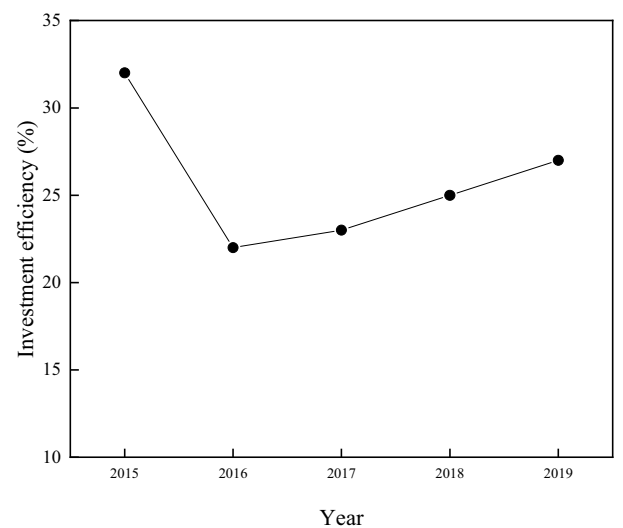

Fig. 5 Proportion of effective investment in clean energy

The results reveal that between 2015 and 2019, effective investments in clean energy account for $32 \%$, $22 \%, 23 \%, 25 \%$ and $27 \%$, respectively. A lot of ineffective investments occurred from 2015 to 2016 and from 2016 to 2017 , but during this period, basically $80 \%$ of the investments of power enterprises were effective. Meanwhile, the study also analyzes the proportion of efficient investment in clean energy investment in these years. The results are shown in Figure 6 below.

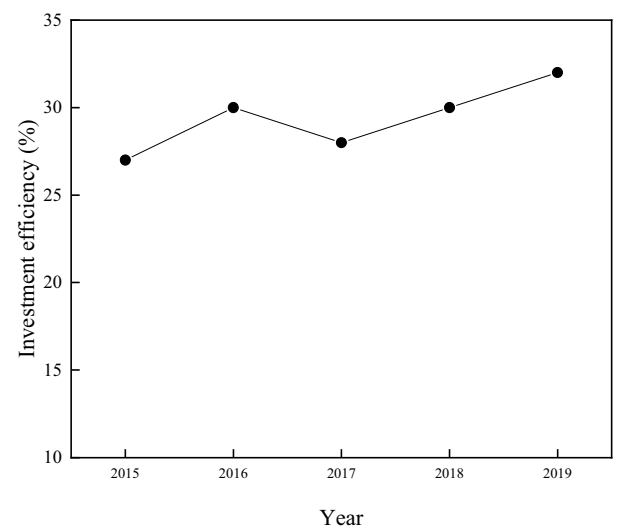

Figure 6. Proportion of efficient investment in clean energy

From 2015 to 2017, the proportion of power enterprises' efficient investment in clean energy fluctuated, being $27 \%, 30 \%$ and $28 \%$ respectively. But after 2017, the proportion of efficient investment increased to $30 \%$ and $32 \%$ respectively. Although the expected income of clean energy in the future cannot be evaluated, it can be predicted that the investment efficiency of clean energy will be definitely improved in the future.

\section{Conclusion}

On the theoretical basis of DEA model, this paper devises corresponding evaluation indexes, analyzes and calculates the investment efficiency of clean energy and changes in efficiency for China's electric power enterprises. The paper mainly draws the following conclusions. Based on the analysis of comprehensive factors influencing 
investment efficiency from 2015 to 2017 , the investment efficiency of overseas clean energy China's electric power enterprises invested in decreased measurably, the comprehensive investment efficiency being $80.5 \%$, $79.1 \%$ and $78.7 \%$ respectively. After 2018 , the overall investment efficiency gradually increased. According to the factor analysis of the ratio of the efficiency of effective investment in clean energy, the proportion of effective investment from 2016 to 2017 was relatively small, being $22 \%$ and $23 \%$ respectively, and subsequently became larger. The factor analysis of the ratio of efficiency of efficient investment in clean energy indicates that the proportion of efficient investment fluctuated remarkably from 2015 to 2017 and increased significantly after 2017 , and it may continue to rise in the future. The study bases itself on the reality and focuses on the hot topic of investment in clean energy at present. The results of this study are scientific and effective, boasting application value. Nevertheless, due to the restriction of the prior conditions, this study fails to categorize and discuss the investment efficiency of different types of power industry. The follow-up study will give further analysis to ensure a comprehensive research.

\section{About the author:}

Ma Chao Nvhan, Xining, Qinghai, September 9, 1979.Education: Postgraduate Title: Senior Economist

Research area: overseas power investment

\section{References}

1. Kittner N, Lill F, Kammen D M. Energy storage deployment and innovation for the clean energy transition[J]. Nature Energy, 2017, 2(9): 1-6.

2. Li $X$, Yang $X$, Xue $H$, et al. Metal-organic frameworks as a platform for clean energy applications[J]. EnergyChem, 2020, 2(2): 100027.

3. Lowitzsch J, Hoicka C E, Van Tulder F J. Renewable energy communities under the 2019 European Clean Energy Package-Governance model for the energy clusters of the future?[J]. Renewable and Sustainable Energy Reviews, 2020, 122: 109489.

4. Obama B. The irreversible momentum of clean energy[M]. Science, 2017, 355(6321): 126-129.

5. Carter E, Yan L, Fu Y, et al. Household transitions to clean energy in a multiprovincial cohort study in China[J]. Nature Sustainability, 2020, 3(1): 42-50.

6. Xie B C, Zhao W, Yin Z L, et al. How much will the residents pay for clean energy? Empirical study using the double bound dichotomous choice method for Tianjin, China[J]. Journal of Cleaner Production, 2019, 241: 118208.

7. Wei J, Duan H, Yan Q. Shale gas: Will it become a new type of clean energy in China?-A perspective of development potential[J]. Journal of Cleaner
Production, 2021, 294: 126257.

8. Tan H, Thurbon E, Kim S Y, et al. Overcoming incumbent resistance to the clean energy shift: How local governments act as change agents in coal power station closures in China[J]. Energy Policy, 2021, 149: 112058 .

9. Chen J, Liu W, Jiang D, et al. Preliminary investigation on the feasibility of a clean CAES system coupled with wind and solar energy in China[J]. Energy, 2017, 127: 462-478.

10. Hongtao L, Wenjia L. The analysis of effects of clean energy power generation[J]. Energy Procedia, 2018, 152: 947-952.

11. Ma Y, Yan J, Sha J, et al. Dynamic simulation of the atmospheric environment improved by a focus on clean energy utilization of resource-based cities in China[J]. Journal of Cleaner Production, 2018, 192: 396-410.

12. Gu F, Wang J, Guo J, et al. How the supply and demand of steam coal affect the investment in clean energy industry? Evidence from China[J]. Resources Policy, 2020, 69: 101788.

13. Isoaho K, Goritz A, Schulz N. Governing clean energy transitions in China and India[J]. The Political Economy of Clean Energy Transitions, 2017: 231-249.

14. Xiao Q, Gao M, Xiao X, et al. A novel grey Riccati-Bernoulli model and its application for the clean energy consumption prediction[J]. Engineering Applications of Artificial Intelligence, 2020, 95: 103863.

15. Wang G, Xu Y, Ren $\mathrm{H}$. Intelligent and ecological coal mining as well as clean utilization technology in China: Review and prospects[J]. International Journal of Mining Science and Technology, 2019, 29(2): 161-169.

16. Wang J, Zhao $\mathrm{T}$, Zhang $\mathrm{X}$. Environmental assessment and investment strategies of provincial industrial sector in China-Analysis based on DEA model[J]. Environmental Impact Assessment Review, 2016, 60: 156-168.

17. Liu Q, Wang S, Zhang W, et al. China's municipal public infrastructure: Estimating construction levels and investment efficiency using the entropy method and a DEA model[J]. Habitat International, 2017, 64: 59-70.

18. Kang Y Q, Xie B C, Wang J, et al. Environmental assessment and investment strategy for China's manufacturing industry: A non-radial DEA based analysis[J]. Journal of Cleaner Production, 2018, 175: 501-511.

19. Tan $X$. China's overseas investment in the energy/resources sector: Its scale, drivers, challenges and implications[J]. Energy Economics, 2013, 36: 750-758.

20. Zhang S, Wang W, Wang L, et al. Review of China's wind power firms internationalization: Status quo, determinants, prospects and policy implications[J]. 
Renewable and Sustainable Energy Reviews, 2015, 43: 1333-1342.

21. Ghemawat P, Hout T. Can China's Companies Conquer the World: The Overlooked Importance of Corporate Power[J]. Foreign Aff., 2016, 95: 86.

22. Duan F, Ji Q, Liu B Y, et al. Energy investment risk assessment for nations along China's Belt \& Road Initiative[J]. Journal of Cleaner Production, 2018, 170: 535-547.

23. Shen W, Power M. Africa and the export of China's clean energy revolution[J]. Third World Quarterly, 2017, 38(3): 678-697.

24. Zeng S, Jiang C, Ma C, et al. Investment efficiency of the new energy industry in China[J]. Energy Economics, 2018, 70: 536-544.

25. He Y, Chen $\mathrm{C}, \mathrm{Hu} \mathrm{Y}$. Managerial overconfidence, internal financing, and investment efficiency: Evidence from China[J]. Research in International Business and Finance, 2019, 47: 501-510.

26. Shahzad F, Rehman I U, Nawaz F, et al. Does family control explain why corporate social responsibility affects investment efficiency?[J]. Corporate Social Responsibility and Environmental Management, 2018, 25(5): 880-888.

27. Li Y, He J, Xiao M. Risk disclosure in annual reports and corporate investment efficiency[J]. International Review of Economics \& Finance, 2019, 63: $138-151$. 